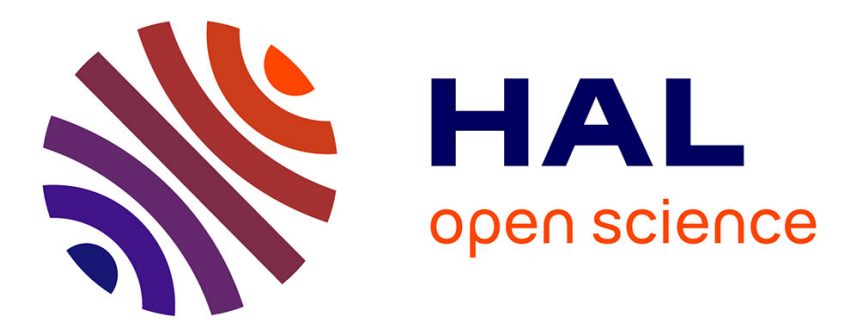

\title{
First steps towards a target laboratory at GANIL
}

C. Stodel, G. Frémont, G. Auger, C. Spitaels

\section{To cite this version:}

C. Stodel, G. Frémont, G. Auger, C. Spitaels. First steps towards a target laboratory at GANIL. 22nd World Conference of the INTDS, Oct 2004, Gaithersburg, United States. pp.112-114, 10.1016/j.nima.2005.12.233 . in2p3-00025672

\section{HAL Id: in2p3-00025672 https://hal.in2p3.fr/in2p3-00025672}

Submitted on 23 Feb 2006

HAL is a multi-disciplinary open access archive for the deposit and dissemination of scientific research documents, whether they are published or not. The documents may come from teaching and research institutions in France or abroad, or from public or private research centers.
L'archive ouverte pluridisciplinaire HAL, est destinée au dépôt et à la diffusion de documents scientifiques de niveau recherche, publiés ou non, émanant des établissements d'enseignement et de recherche français ou étrangers, des laboratoires publics ou privés. 


\title{
FIRST STEPS TOWARDS A TARGET LABORATORY AT GANIL
}

\author{
CH. STODEL, G. FRÉMONT, G. AUGER*, C. SPITAËLS \\ GANIL, B.P. 5027, F-14076 CAEN Cedex 5, France \\ *Collège de France, 11 place Marcelin Berthelot, F-75231 PARIS Cedex 5, France
}

\begin{abstract}
The development of large-isotopically enriched ${ }^{208} \mathrm{~Pb}$ and ${ }^{209} \mathrm{Bi}$ targets and the production of thin carbon films are described. Their use on rotating wheels in heavy-ion fusion reactions with intense ${ }^{58} \mathrm{Fe},{ }^{76} \mathrm{Ge}$ and ${ }^{48} \mathrm{Ca}$ beams is reported.
\end{abstract}

\section{Introduction}

GANIL is a national facility for nuclear physics research where beams from carbon to uranium can be accelerated up to $95 \mathrm{MeV} / \mathrm{u}$ using two cyclotrons. Some of the experiments require specific targets. For instance, since 1997, GANIL, LPC (Caen) and SPhN-DAPNIA (Saclay), supported by the CNRS and CEA, used the velocity filter LISE3 to investigate nuclei at the limits of stability, such as superheavy elements. In these measurements, the main difficulty comes from the very low counting rate of the sought-after events and it is necessary to optimize each aspect of the experimental setup: beam, targets, velocity filter performance and detection. As these experiments last several weeks and the thin targets must sustain intense beams, high quality targets should be available in quantity. For last year's experiments (search for a new isotope of element $\mathrm{Z}=114$ and spectroscopy of ${ }^{251} \mathrm{Md}$ via the reactions ${ }^{208} \mathrm{~Pb}\left({ }^{76} \mathrm{Ge}, 1 \mathrm{n}\right){ }^{283} 114$ and ${ }^{209} \mathrm{Bi}\left({ }^{48} \mathrm{Ca}, 2 \mathrm{n}+\alpha\right){ }^{251} \mathrm{Md}$, it was important that the numerous special targets be made on-site. That is why a target laboratory has been under development since 2003.

\section{Target considerations}

Certain specific parameters define the criteria for targets in heavy-ion fusion reactions. Considering the energy and angular straggling of the projectiles and evaporation residues in the target and the narrow energy window of $\sim 10 \mathrm{MeV}$ for the desired reaction, a target thickness of $300-400 \mu \mathrm{g} / \mathrm{cm}^{2}$ is recommended. The melting points of lead and bismuth are relatively low and the targets have to sustain beams of typically $2-3 \mathrm{~mm}$ in diameter with intensities of up to $1 \mu \mathrm{Ap}$. 
To help with the heat dissipation problem, the target material is deposited onto mechanically strong heat conducting layers of $35 \mu \mathrm{g} / \mathrm{cm}^{2}$ of carbon. A thin protective layer of about $5 \mu \mathrm{g} / \mathrm{cm}^{2}$ of sublimed carbon covers the target surface in the downstream direction to reduce sputtering loss. So for the abovementioned experiments, two wheels, with a diameter of $670 \mathrm{~mm}$, bearing either 36 short or 18 long targets were mounted on a common axis to rotate together at $2000 \mathrm{rpm}$. Targets are mounted on the upstream wheel and carbon foils for charge equilibration on the other one (see Figure 1).

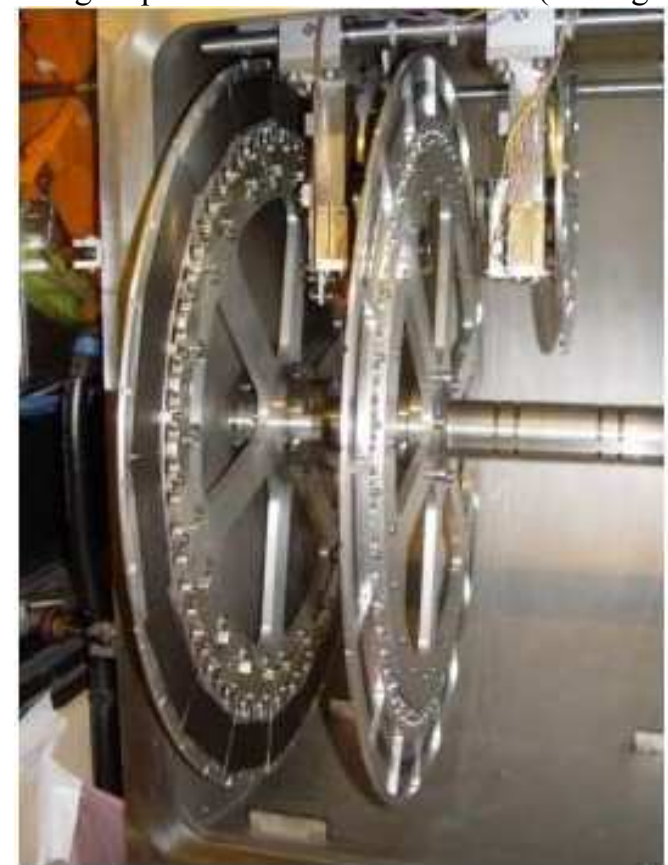

Figure 1: Target chamber with the two wheels bearing $18 \mathrm{~Pb}$ or $\mathrm{Bi}$ targets and 18 carbon charge equilibration films.

\section{Production of targets}

At present, the target laboratory is equipped with two evaporators, one for carbon layers and one for lead or bismuth targets.

\subsection{Carbon films}

Thin self-supporting carbon films are produced by resistance evaporation of a carbon rod under high vacuum as described earlier [1-3]. A carbon rod for spectrography, $88 \mathrm{~mm}$ long and $3 \mathrm{~mm}$ in diameter with its ends connected to 
copper electrodes is placed in a vertical position in the center of the apparatus. Eight glass plates of $\left(100 * 140 \mathrm{~mm}^{2}\right)$ are arranged at an average distance of 170 $\mathrm{mm}$ around the carbon electrode to collect the evaporated carbon. The plates are treated with a saturated aqueous solution of betaïne-monohydrate/saccharose (7:1) as parting agent [2]. The carbon sublimation is performed at an electrical current of $\sim 200$ A for a few tens of seconds. With one evaporation cycle, 24 carbon targets $\left(100 * 30 \mathrm{~mm}^{2}\right)$ with an areal density of $\cong 35 \mu \mathrm{g} / \mathrm{cm}^{2}$ are produced. About $50 \%$ of them are considered to have good enough quality to be used. The thickness of the carbon deposited on the glass plates is not well controlled and cannot be reproduced accurately. No targets thicker than $35 \mu \mathrm{g} / \mathrm{cm}^{2}$ could be produced with this method. The carbon deposits are floated off of the glass plates onto water and picked up on target frames on which they stick by adhesion. These resulting films are dried and additionally glued to the frames. These films are used as charge equilibration foils, backings for targets and some with thinner thickness for emissive films for detectors.

\subsection{Lead and bismuth targets}

The $35 \mu \mathrm{g} / \mathrm{cm}^{2}$ carbon backings on aluminum frames are covered by a mask, leaving a quasi-rectangular opening over most of their $\approx 15 \mathrm{~cm}^{2}$ of selfsupporting surface. A set of six frames is clamped to a rotating $(60 \mathrm{rpm})$ holder at $30 \mathrm{~mm}$ from a tungsten boat holding $0.14 \mathrm{~g}$ of isotopically enriched lead $\left({ }^{208} \mathrm{~Pb}\right)$ or bismuth for evaporation. The evaporation rate is controlled with a quartz balance. In one run, six targets of $350 \pm 25 \mu \mathrm{g} / \mathrm{cm}^{2}$ thickness are produced with a deposition yield of $23 \%$. A second layer of carbon is then deposited by sublimation. 


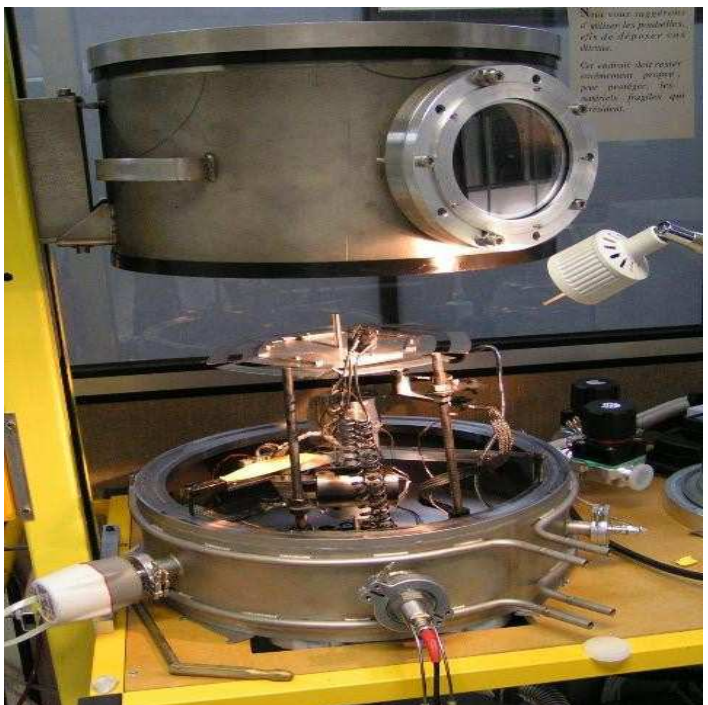

Figure 2: System for evaporating ${ }^{208} \mathrm{~Pb}$ or $\mathrm{Bi}$ onto rotating carbon backings.

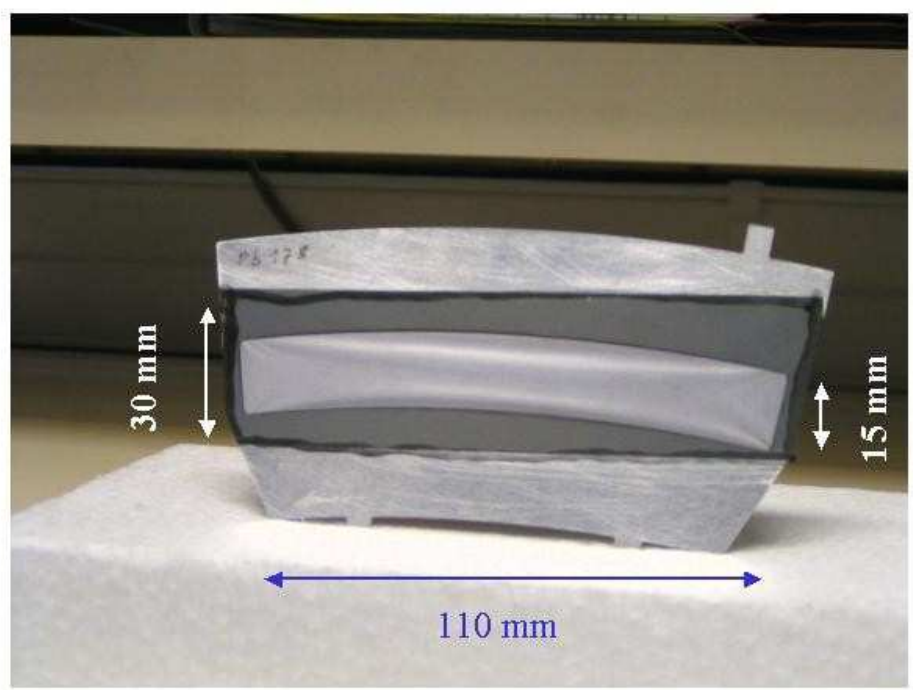

Figure 3: Enriched ${ }^{208} \mathrm{~Pb}$ target, $15 \mathrm{~mm}$ in height, $100 \mathrm{~mm}$ long: $\mathrm{C} 35 \mu \mathrm{g} / \mathrm{cm}^{2}+\mathrm{Pb} 350 \mu \mathrm{g} / \mathrm{cm}^{2}+$ C $5 \mu \mathrm{g} / \mathrm{cm}^{2}$. 


\section{Target performance}

For the 2003 experiments, about $200{ }^{208} \mathrm{~Pb}$ targets (Fig. 3) and $50{ }^{209} \mathrm{Bi}$ targets of $350 \mu \mathrm{g} / \mathrm{cm}^{2}$ thickness sandwiched between 35 and $5 \mu \mathrm{g} / \mathrm{cm}^{2}$ of carbon were used. Three target frames are mounted on a holder in the form of a sector of a circle (Figure 4) and six such holders are clamped on the rotating wheels as shown in Figure 1. One sixth of the surface of one segment is free of material to perform test measurement and calibrate the wheel rotation.

A first test irradiation with a ${ }^{58} \mathrm{Fe}$ beam on ${ }^{208} \mathrm{~Pb}$ took place in order to produce isotopes of hassium $(\mathrm{Z}=108)$ and reproduce the known the excitation function from the GSI [4]. ${ }^{208} \mathrm{~Pb}$ targets rotating at $1500 \mathrm{rpm}$ were then irradiated for nearly three weeks with a ${ }^{76} \mathrm{Ge}^{10+}$ beam of $5 \mathrm{MeV} / \mathrm{u}$ at $0.8 \mu \mathrm{Ap}$ (average). The power dissipated in the targets was $6 \mathrm{~W}$. The integrated beam was $5 * 10^{18}$ particles. Meanwhile, we replaced the targets every five days. The target quality and the synchronization between the beam pulses and the wheel rotation were continuously monitored with a silicon surface barrier detector measuring scattered particles and $\mathrm{a} \mathrm{BaF}_{2}$ crystal detecting the $\gamma$-rays of the reaction products around the targets.

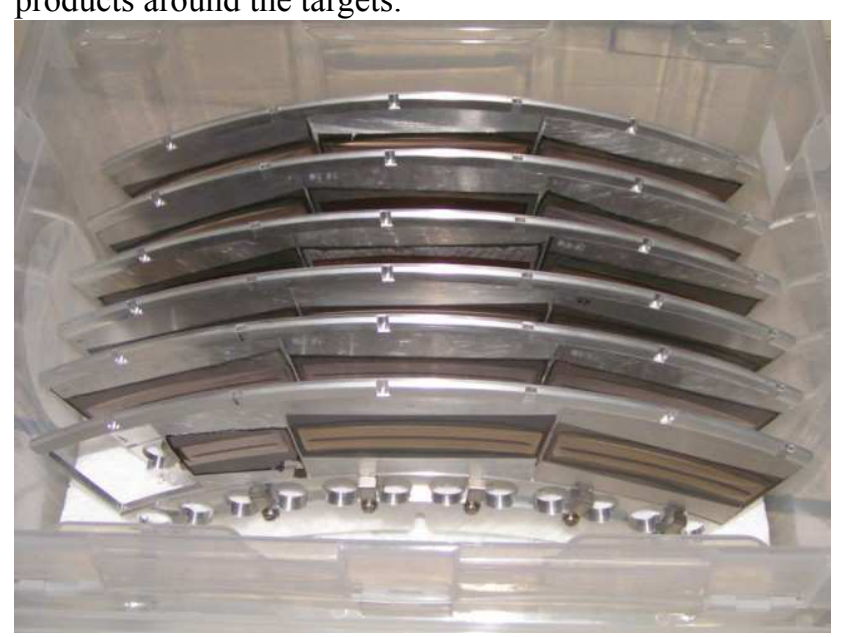

Figure $4:{ }^{208} \mathrm{~Pb}$ targets on segments of the wheel after irradiation.

A similar experiment took place in December 2003, when ${ }^{209} \mathrm{Bi}$ targets were irradiated for 10 days with a ${ }^{48} \mathrm{Ca}$ beam of $0.125 \mu \mathrm{Ap}$ losing $0.6 \mathrm{~W}$ in the targets. 


\section{Other developments}

In experiments already performed, the time-of-flight detector used emissive foils of aluminized Mylar $(1.5 \mu \mathrm{m})$. To reduce the energy and angular straggling in this detector of low energy superheavy evaporation residues, new foils are being produced and are under test: $\mathrm{C}\left(35 \mu \mathrm{g} / \mathrm{cm}^{2}\right.$, diam $\left.70 \mathrm{~mm}\right)$, VYNS foils $(0.1 \mu \mathrm{m}$, diam $100 \mathrm{~mm})$, Mylar $+\mathrm{Al}+\mathrm{CsI}(0.9+0.15+0.04 \mu \mathrm{m}$, diam $100 \mathrm{~mm})$.

\section{Conclusions and perspectives}

Many high quality isotopic ${ }^{208} \mathrm{~Pb}$ and ${ }^{209} \mathrm{Bi}$ targets were produced in the new target laboratory of GANIL. Their behavior under intense irradiation was satisfactory. Development of the evaporation technique is being extended to the preparation of thin films for detectors.

In the future, we would like to extend the production of thin films to various materials requested for targets, such as nickel or germanium thin targets, and detectors needed for GANIL experiments.

\section{Acknowledgments}

We wish to thank Bettina Lommel and her group from the GSI for helpful advice on the evaporation techniques. We are greatly indebted to the IReS (Strasbourg) and Marie-Antoinette Saettel for equipment ceded to GANIL.

\section{References}

1. W. Thalheimer et al., Cryst. Res. Technol 34. (1999) 175.

2. P. Maier-Komor, Nucl. Instrum. Meth. 102. (1972) 485.

3. H. Folger et al., Nucl. Instrum. Meth. A334. (1993) 69.

4. S. Hofmann et al., Nucl. Phys. A734. (2004)93. 